\title{
Public data art's potential for digital placemaking
}

Georgescu Paquin, Alexandra ${ }^{a}$

aGrup de Recerca Turisme, Cultura i Territori, Campus de Turisme, Gastronomia i Hoteleria CETT-UB, España, alexandra.georgescu@cett.cat

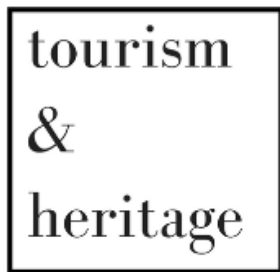

J O U R N A L

\section{ARTICLE INFO}

Article history:

Received 19 March 2019

Accepted 26 June 2019

Published 27 June 2019

Keywords:

Augmented space; Data art;

Data visualization;

Placemaking; Public space.

\section{A B S T RAC T}

Data-based public art is an innovating new form of digital art which presence is increasing in the cities datascape. Data as a medium provides a special relationship with time and space by connecting the context of data mining to the one of its exhibition. The virtual component of data art opens an augmented space, where the different dimensions of data are mediated. This essay analyses how this new art form can contribute to a creative and digital placemaking of a city by offering a special sensory experience as well as renewing the storytelling of its space. Three case studies support the analysis. "Living connections", projected on an emblematic bridge in Montreal, contributes to a spectacular placemaking. "Interconnected", a data sculpture in Charlotte airport, relates to infrastructure placemaking. Finally, "Herald/Harbinger" connects the industrialized society with nature in a global connection. The results participate to the reflection on the nature and specificity of data art as well as enhancing its potential of transforming public space by engaging a specific relation with time, place and people.

\section{INTRODUCTION}

Contemporary art in public spaces can contribute to placemaking strategies. It can foster collective cohesion by providing new meanings to the city. Site-specific art change public spaces into dynamic spaces, that are perpetually being lost and found (Urbonas, Lui, \& Freeman, 2017). Placemaking is not only a tool to rediscover and renew public spaces but can also modify the image of a city. From a tourism point of view, organic and planned placemaking are an essential part of tourism destination development and marketing (Lew, 2017). Cities have had the need to differentiate themselves for more than two decades in order to draw visitors and retain visitors (Markusen, 2010), for example by innovative, powerful art.

Data art has evolved quickly in the last decade. The practice that was mainly based on a diffusion on a screen now also materializes itself in the public space under different formats and shapes. From temporary artworks in festival contexts, permanent ones are increasingly conceived as part of the cityscape, especially in North America. Because of the 
particularity of its medium -the data-, data art provides a specific experience for the viewers, different from other public art forms. However, beyond the medium itself, public data-based artworks could be included in the family of "urban media art". This contemporary form of public art responds to the issues and discourses of our time and plays a role in our current urban context (Pop, Toft, Calvillo, \& Wright, 2016).

Technology is central to this practice. It constitutes the medium and is reflected in the construction of the message, that addresses the contemporary, technologically advanced society (Pop et al., 2016). Data art thus has a communicative aspect that was already explored in media facades and urban screens (Pop, Tscherteu, Stalder, \& Struppek, 2012). Data-based artworks add a layer of signification on a site, because of its medium that is already socially charged with meaning, through the interpretation of the data. Historically, two approaches have been taken on modern media technologies into the spatial dynamics of the city: spectacle and surveillance (McQuire, 2008). Data art allows to address other modern issues, such as environment, demographic, politics, social media, etc., with a multiple variety of formats and approaches, such as ludic, poetic, amongst others. Since data (that is, the medium) are collected from nature or human production, data art renders a reflection of our society. Through various forms such as sculpture, painting or onscreen, data public art also uses urban infrastructure and architecture as interface and display device.

The virtual component of data art extends the concept of space to "augmented space" (Manovich, 2006) in which the artwork connects a collectivity to both a physical and a virtual space. In that context, how can data art contribute to placemaking? This paper presents a reflection on this new and innovative form of art that is still defining itself. It aims at understanding how it provides another narrative of the space where it is displayed as well as a connection to a broader context. In other words, how the data public artwork mediates time and space through the use of this particular material. This essay could contribute to the reflection on the nature and specificity of data art as well as enhance its potential of transforming public space. The essay focuses on the specific relation data art engages with time, place and people, which differentiates it from other types of new media art. The first part of the essay develops the concept of placemaking, whose use has increased since its conceptualization around fifty years ago. In the second part of the essay, data art is defined with its specificities and types of data used as a medium. Three case studies will then help explore different types of mediation: the first one, "Living Connections", a real-time installation on the Jacques Cartier Bridge in Montreal, offers a reflection of its surrounding with a spectacular type of placemaking. It is followed by "Interconnections", a data sculpture at Charlotte International airport that offers a poetic take on a place of transit. Finally, "Herald / Harbinger" links our industrialized city with nature and its impact on it.

\section{PLACEMAKING PRACTICES IN ART}

The concept of placemaking is nowadays mainstream. It refers to various types of actions performed by different actors, leading to different outcomes in public space. The concept is used in various ways that underline different logics through different spellings (Lew, 2017). Placemaking as a unified word could be defined as "catching on as another way to improve the quality of various places in a neighborhood, and by extension, the community and region in which those places are located as well" (Wyckoff, 2014: 1). Moreover, with 
placemaking the visitor can engage with the metanarratives that construct the "sight sacralization" (Lew, 2017; MacCannell, 2013). The concept has evolved throughout the years and has been the subject of conferences and focus of research centers, such as Project for Public Spaces (PPS, founded by Fred Kent), MSU Land Policy Institute, Urban Land Institute, or the Institute for Quality Communities.

Placemaking has been practiced since the 1960's mainly by architects, urban planners and urban designers, but it has now reached other sectors such as tourism (Lew, 2017). The aim of improving the quality of a public place for its community is not new and can be traced back to the Greek agora (Silberberg, 2013), but placemaking comes as a reaction to the loss of public splace after the industrialization process. The concept takes it roots in the works of Jane Jacobs, Kevin Lynch and William Whyte, recognizing the importance of communities in the use and design of public spaces (Silberberg, 2013). In a review of literature produced on the topic, Strydom, Puren, \& Drewes (2018) extracted three different phases that comes from a top-down to a bottom-up approach of placemaking. For the authors, from the 1970's to the 1990's, placemaking was about spatial arrangement and design of a setting following the decisions of expert policy makers. A first shift occurred in the process of decision-making, when stakeholders' viewpoints took an increasing role. Also, placemaking was no more seen as a physical end-product, but as a democratic process. Finally, since 2010, placemaking has been seen as an empowering tool, allowing not only the experts but all people and citizens to perform this practice. People are now at the center of this definition, either because we design the city for them, either by including them in the process (Tomitsch, 2016). In practice,

placemaking seeks to build or improve public space, spark public discourse, create beauty and delight, engender civic pride, connect neighborhoods, support community health and safety, grow social justice, catalyze economic development, promote environmental sustainability, and of course nurture an authentic "sense of place." (Silberberg, 2013: 2)

Lew (2017) divides two types of placemaking: organic and planned. The first is associated with bottom-up, local initiatives, minor initiatives. The other one corresponds to a planned and often top-down professional approach that shapes people's perceptions and behaviors (p. 449).

Placemaking is thus considered now as a process, the end being the improvement of creating quality places (Wyckoff, 2014). The author, professor at MSU Land Policy Institute, defines quality places with its key elements, amongst which are arts, culture and creativity. He develops four design types of placemaking: standard placemaking, that is an incremental process of improvements over time, and three specialized types that target particular goals: strategic, creative and tactical placemaking. In his words, strategic placemaking aims at creating quality places that are "uniquely attractive to talented workers" (Wyckoff, 2014: 5), and can act like a catalyst to revitalize a whole neighborhood or a city through major investments (Lew, 2017). Creative placemaking is a strategy that institutionalizes arts, culture and creative thinking, using arts (and not just urban design elements) to enhance the attractivity and interest of the place. Finally, tactical placemaking (sometimes linked to guerrilla or hacking initiatives (Mansilla \& Perkis, 2016; Tomitsch, 2016) refers to usually temporary smaller-scale interventions with a bottom-up approach, in a more informal manner and from local actors. Public data art, as a creative process, could inscribe itself as creative or tactical placemaking, depending on the context, the process and the goals to achieve. 


\subsection{Creative and digital placemaking}

The term "creative placemaking" was coined in 2010 by Ann Markusen and Anne Gadwa when they wrote the White Paper on Creative Placemaking for National Endowment for the Arts (Markusen \& Gadwa, 2010). They defined it as follows: "Creative placemaking animates public and private spaces, rejuvenates structures and streetscapes, improves local business viability and public safety, and brings diverse people together to celebrate, inspire, and be inspired." (p. 3) For the authors, it has an economic-development goal component, but also livability. Livable sites refer to ones that are repurposed with a more attractive function that offers a uniqueness of the setting (Strydom, Puren, \& Drewes, 2018: 166). More importantly, putting people and community at the center of the initiative could help avoiding excessively economic-centered decisions that would provoke a gentrification process or falling into simulacra and disneyification that would lead to the opposite effect to placemaking, that is, the loss of the sense of place. Greg Richards (2016) identifies a tripartite relationship between meaning, materials and creativity for an effective strategy of placemaking in terms of creation process. Creativity is embodied in material forms, which in turn, brings meaning to the place.

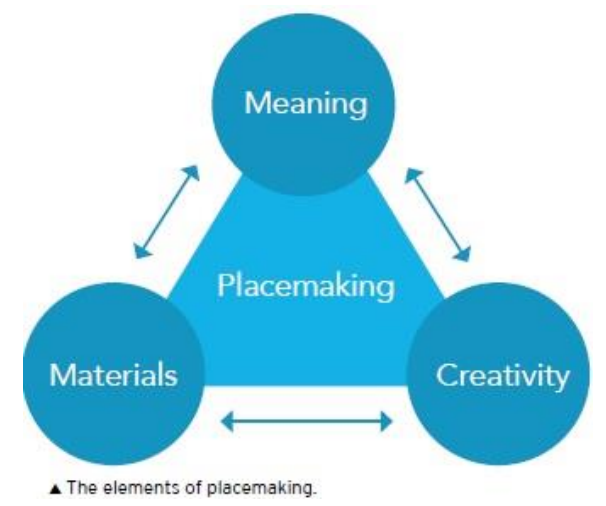

Figure 1. The elements of placemaking. Source: Richards (2016)

Digital art, in this context, can provide new relationships to a place or provoke new sensory experiences in a way that can also be dynamic and renewable. Interactivity allows people to engage with the artwork, which, accordingly, mediates the space. Digital placemaking involves a redefinition of the notion of space, from the physical to an augmented one: it is a "process of using digital media or shaping experiences that are citizen-centric, in modes of "augmenting" and positively reinforcing urban place." (Tomitsch, 2016: 340)

Digital media can shape citizen's experiences in public spaces with three types of digital placemaking (Tomitsch, 2016): community, spectacle, infrastructure. Community placemaking is citizen-focused, with a design that responds to the needs and desires of citizens, corresponding to a more organic idea that empowers citizen in bottom-up and middle-out initiatives. Spectacle placemaking "refers to the use of large-scale digital media for creating new, temporary destinations in cities." (Tomitsch, 2016: 343) But this strategy could also apply for permanent public works, giving a uniqueness and spectacular approach to the city. Infrastructure placemaking, as its name suggests, improves the existing infrastructure of cities. It can be in a playful way or for pragmatic purposes. The case studies further analyzed, will first develop the idea of a spectacular placemaking through a lightning installation. Then, infrastructure placemaking will be explored by giving a new light to the experience of an airport. Finally, an example of community- 
centered placemaking will be illustrated by the content of the artwork, rather than by its placemaking process.

\section{DATA ART}

Public data-driven art is a recent phenomenon that has been increasing since the last decade, consequently with the rise of data production. Nonetheless, data visualization practice, from which it sprouts out, could be traced back to 6000 years ago, according to the father of data visualization Edward Tufte (1990). The modern practice of data visualization stems from the graphical representation of quantitative data, which Descartes had already introduced in the $17^{\text {th }}$ century with the graphical representation of functions. However, Tufte refers to systems of representations that do not reflect the digital age context (Li, 2018; Manovich, 2002). The use of computers allows to visualize a larger set of data as well as dynamic and navigable displays through different types of representation of a phenomenon (Corby, 2008; Manovich, 2002).

Two different approaches could be differentiated for data visualization's aim: functional and aesthetic. In the first one, data visualization translates a big quantity of data into visual information that allows decision-makers to understand a phenomenon in order to take decisions. It provides accuracy and has to be comprehensible by the viewer (Arruabarrena, 2015). It conveys a message or draws patterns hidden in the represented data through metaphors that users can quickly understand. In contrast, aesthetic information visualizations are more concerned with presenting a subjective impression of a data set by eliciting a visceral or emotive response from the user (Ramirez Gaviria, 2008: 479). This kind of visualization is seen as an aesthetic practice (Bihanic, 2018; Evers \& Nack, 2016; Freeman, Starks, \& Sandler, 2018; Li, 2018) because "the process of visualization involves translation of data into visual, symbolic form or pictures" (Corby, 2008, p. 462). Accuracy is therefore not required; it raises questions rather than answering them or, to quote Kosara (2007), to "communicate a concern, rather than to show data" (p. 634). As a matter of fact, Viégas \& Wattenberg (2007) consider that "they are committing various sins of visual analytics" (p. 190). Between science and arts, data art, or data visualization, has switched from "a tool in scientific inquiry that necessitated the statistical mapping of data" to a new "hybridized art form" (Legrady \& Forbes, 2017: 200) As Li (2008) suggests, "the perception of the power of big data can also enhance the aesthetic experience of our society and everyday lives" (p. 309). For the author, applying aesthetics to visualization can both allow the scientific use and trigger emotions.

Some authors see the experience of data art through a new realm, that is data sublime (Fedorova, 2012; Fortin, 2016; McCormack \& Dorin, 2001). The sublime, in that context, is referred as "providing an all-sensory engagement with the reality of the unpresentable, a unitary and intersubjective experience of a "stretched" identity" (Fedorova, 2012: 34). In contrast, Manovich (2002) argues that through the concept of data mapping, data visualization represents the anti-sublime, as it grasps and transform quantified data that in itself is not visual into a visual representation.

Data-based creative art practice can be divided into two broad categories: static and dynamic (Li, 2018). On the one hand, data can be represented and displayed in a way that does not evolve. On the other hand, data can be represented and displayed in real-time, never showing twice the same. Furthermore, it could be analyzed through its relationship with its surroundings, exposing two other categories: data art can be a) independent or b) 
linked to the context where it is presented (Legrady \& Forbes, 2017). In the second case, the data could be mined on the site, so the artwork reflects its surroundings; it could be the mood of a city, a crowd, mobility, etc. We could add a third case, where different spaces are linked: the one of data mining and the one where it is displayed. If we combine the typologies from both previous authors, the first one being the relationship to time, the other to space, we could divide four types of time and space interrelations between data collection and their display:

1. Here and now: generating real-time content with data mined in the same space where the artwork is displayed. Dynamic.

2. There and now: generating real-time content with data collected elsewhere. Dynamic.

3. Here and before: data collected in situ but in a fixed period prior to its exhibition.

4. There and before: data collected in a different location than the one where the artwork is displayed, and in a fixed period prior to its exhibition.

Because data are collected and transmitted in real time in the first two categories, the works of art are dynamics, whereas the other two categories are most likely to exhibit static data, fixed in a previous time.

Data brings a complexity to the work because it connects different spaces and time, can be dynamic or static, and can materialize in different visualization forms. The form that data art takes vary from the screen to paintings to using structures as display to 3D representation, or data sculpture, that are also called "data materialization" (Starrett, Reiser, \& Pacio, 2018).

\subsection{Data as material}

Data art, as a practice, is still defining itself, more precisely because of the lack of conceptualization of data as an art material (Freeman et al., 2018). Data is considered as a measuring value that helps us understanding a phenomenon more deeply (Freeman et al., 2018). It plays a major role in our modern digital world, for its collection has been exponential through social networks and all the devices that allow personal mobile phones, amongst others. Data could be defined as machine-readable, "figures from databases, raw data, data collected by search engines, calculations and statistics (geographical, political, climatic, financial)" (Grugier, 2016: para.3). Data in this type of art is processed through a computer and represented in a visual form that constructs meaning (Legrady \& Forbes, 2017). Freeman, Starks \& Sandler (2018) propose a taxonomy to describe data in an objective way when used as an art material: its origin, type of license (closed, open or shared, depending on how public or from whom the data can be accessed), relation between time and space, translation type and disclosure of data.

The source or origin of data could thus be of biological or environmental nature, often captured by sensors. It could be for example a heart-rate, or it could be taken from the natural world. The non-living data refers to physical object or device, generated by a machine. The social context of data production can be commercial, engendered by a corporate entity, or by individuals, representing their searches or postings on internet for example. A social group can also be a source where data could be collected, for example through their voting preferences. Finally, data can be produced by the state, that is, a 
government or a ruling authority, for example through legal documents. Its format of existence has five different types of relations between time and space: live data are captured in real time, but not necessarily disseminated at the same time: that would be real-time data, where the data is created, captured and disseminated simultaneously. It is thus dynamic and in constant change. Static data, taken from archives or historical datasets, does not change but can grow over time. Geospatial data is linked to a specific space, while temporal data is based on a specific time. The following case studies will focus on the most available information of the data used, that is the nature of its origin, its social context and the relation between time and space.

\section{MEDIATING TIME AND PLACE IN THE DATASCAPE: 3 CASE STUDIES}

As we have seen, data art presents a complexity of mediation possibilities due to the multiple dimensions of data as material. It thus mediates time and space through the data mining time and space crossing with its display. When data art is temporary, displayed or performed in a specific context, it contributes to the dynamism of the city and its creativity. However, it can be limited to spectacle placemaking, by representing a exceptional event that gives a partial and temporary new light to a place. When they are permanent (or semi-permanent), these artworks contribute to the datascape. Machin (2000) defines datascape as a readable landscape that provides information to the tourist (p. 366), but we refer to it as the one that interprets the available data produced, then transforms it and finally displays it in a digital and mediatic landscape. In that sense, datascape can be considered as a next step to the mediascape as defined by Appadurai (1990). The author defines those types of landscapes as:

image-centered, narrative-based accounts of strips of reality, and what they offer to those who experience and transform them is a series of elements [...] out of which scripts can be formed of imagined lives, their own as well as those of others living in other places. (p. 299)

The first case study, "Living Connections", contributes to the datascape of Montreal, as it displays in real time the "pulse of the city" in LED lights on an iconic bridge. It has won the prize of interactive innovation at South by Southwest festival (SXSW) in the category "smart cities". The second one, "Interconnected", is located in Charlotte international airport, one of the main airports of United States and represents the movements of and around the infrastructure. Finally, "Herald/Harbinger" links downtown Calgary to a glacier in Banff National Park, in Canada.

\subsection{Reflection of the surroundings through spectacle}

For the city of Montreal's 375th and Canada's 150th anniversaries, both taking place in 2017, Jacques Cartier and Champlain Bridges Incorporated produced a large-scale interactive light project for the Jacques Cartier Bridge in Montreal. More than 50 small and large-scale urban projects were put in place to enhance the city and its experience through art and heritage. The flagship project, which will last ten years, is called "Living Connections" (see figure 2) and was conceived by the internationally renowned Montreal 
studios Moment Factory with six collaborators, and a total of over 200 people working on the project.

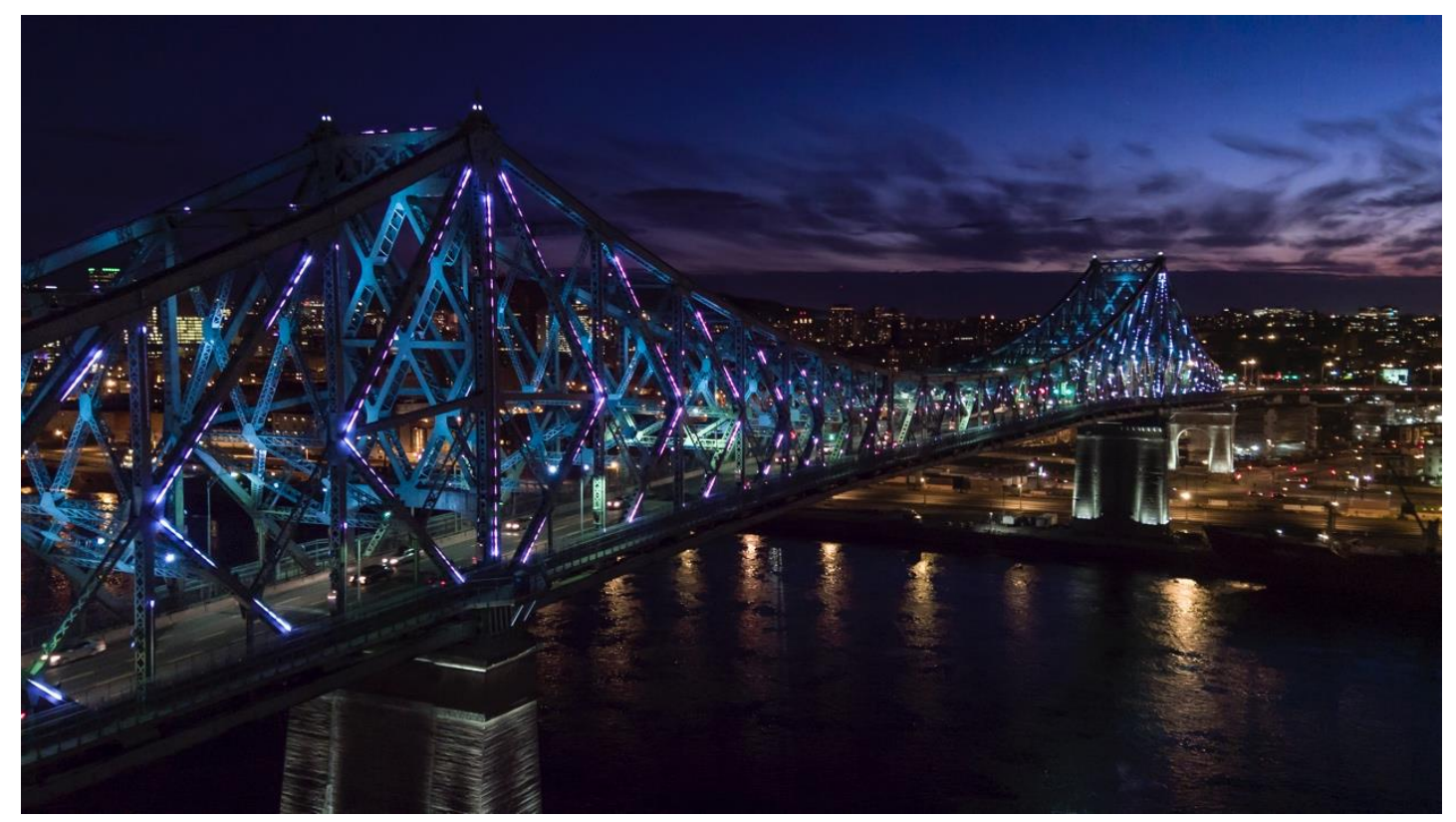

Figure 2. "Living Connections", Moment Factory, 2017-ongoing. Photo: courtesy of Moment Factory studios.

This impressive project cost \$CAD 39,5 million, 30 of which came from the federal government via the Crown corporation, which owns and runs the bridge (Everett-Green, 2017) as well as from The Society for the Celebration of Montréal's 375th anniversary. Its inauguration created a big event, attracting 400,000 spectators.

2,807 LED lights were installed on the bridge steel structure with the help of more than 10 $\mathrm{km}$ of cables for data transfer and electrical power. A dominant color represents each season, gradually changing daily from orange in the summer, to red during fall, blue in the winter and green during spring. Then, the lights react to twitter rants in real time, changing their intensity, speed and density according to the hashtags that the system translates: \#IlluminationMtl, \#Montreal, \#Mtl, \#Mtlmoments.

Sensors track the passage of vehicles, bikes and pedestrians. Every hour and half hour, those data are blended with other ones and displayed through special animations. Also, every hour at night, a compilation of data on weather, traffic, news, and major events amongst other is translated into a five-minute animation. A dominant color is associated to the topic that is most discussed in Montreal media: blue for sport, red for society, purple for culture, light blue for technology, green for environment and pink for institutions. After thirty minutes, there is a minute of scintillation.

The bridge is emblematic to the city. Montreal has a complex hydrographic network, so its bridges are directly linked to its daily dynamics as well as to the history of its urban development. Inaugurated in 1930 under the name of Harbor Bridge after four year of construction, it was renamed Jacques Cartier Bridge four years later in honor of the French explorer and cartographer. The five-lanes bridge links Montreal to Longueuil suburb for motorists, pedestrians and cyclists. During the summer, an important fireworks festival can be enjoyed freely on the bridge, which is closed for the occasion, offering privileged 
upper viewpoints. It is not only a transit space, but also one of collective meeting during special events.

Using this bridge to host the data art emphasizes the industrial structure and its importance in the skyline of the city. It is presented as the "first connected bridge", a feature that is highlighted in the title of the work, "Living Connections". The title gives a double meaning to the artwork, referring to the connections between all the data produced by its surroundings and captured to be translated into lights. But also, the "living" refers to the dynamism of the work, which acts as a living organism responding to the living pulse of the city.

"Living Connections" uses both living and non-living data, some of which are displayed in real time, some are temporary. Apart from the twitter rants, the other types of data are not transparent and are presented as the "general pulse of the city" (Moment Factory, 2019). It is not clear what kind of data correspond to the news about Montreal: are they defined in a geographical space or according to the topics that mention Montreal? Thus, the work represents the pulse of the city metaphorically, but, even though the work does not aim at comprehension, it does not provide any clue to approach its interpretation or to know how to engage with it. As the journalist Robert Everett-Green (2017) puts it, "If you see lots of red, you may not know whether the bridge is getting sociable or signalling the turning of the leaves in autumn." (para.9) "Living connections" present a spectacular placemaking, monumentalizing the structure (already considered a landmark), and giving it a plus value as well as a branding for the city. In fact, it is presented as giving a "signature" to the city (Moment Factory, 2019), like the "starchitecture" was aiming at the turn of the $21^{\text {st }}$ century.

Transforming this location provides an experience to the viewer (Lew, 2017: 451), by changing the city at night with the animations that can be viewed from different places. A map available on the website enhances this feature (see figure 3), providing the best viewpoints to the visitors. Uniqueness and spectacle are the values that enhance the location.

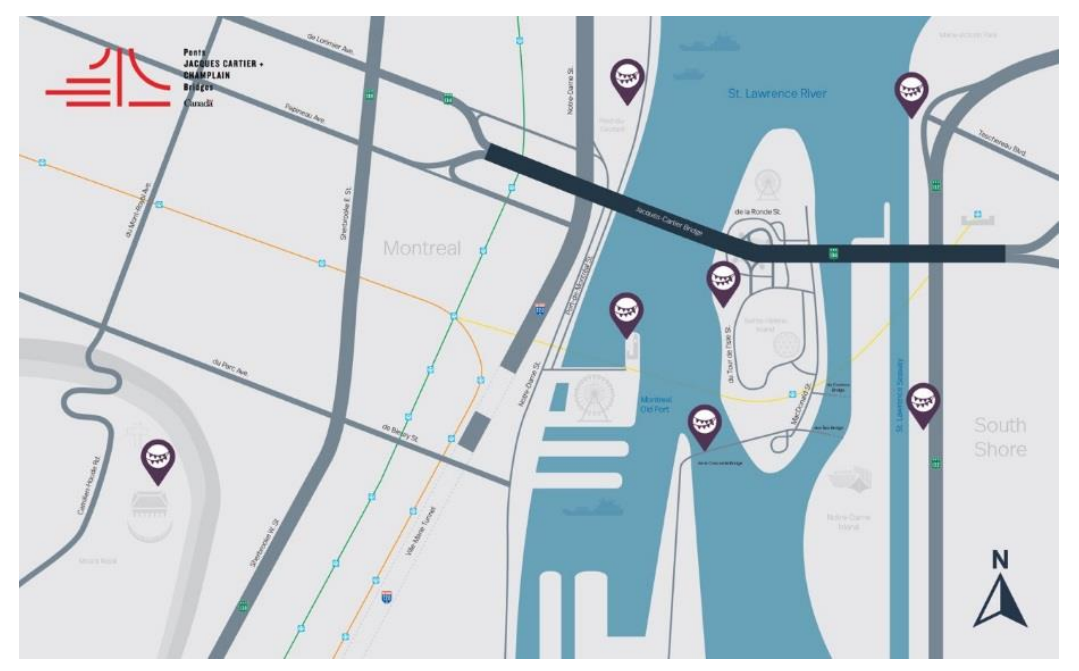

Figure 3. Best recommended viewpoints to see "Living Connections". Source: https://jacquescartierchamplain.ca/best-view-spots/?lang=en 


\subsection{Poetics of a place of transit}

Another project was branded as "unique" for being the nation's largest data-driven digital public art installation, with a title that also refers to the connection provided by the data. "Interconnected", a work by the Los Angeles-based artist Refik Anadol, has become a permanent feature of Charlotte Douglas International Airport (CLT), through which 46 million people transited in 2017. The airport is currently expanding in the context of Destination CLT initiative, which plans to renovate the concourses and expand CLT's roadways, curb front, airfield and terminal through 2035. The first phase of Concourse A, a 21,350 square meter expansion was terminated in July 2018 with nine new gates. "Interconnected" was inaugurated during that occasion, thanks to the CLT Airport public program that, since 1990, "enhance the passenger experience while promoting the City of Charlotte and the surrounding region" (CLT Art Program). "Interconnected" was chosen by the Charlotte's Public Art Commission in a national call and was managed by the Arts \& Science Council. It cost US \$2,9 million coming from airport user and vendor fees as part of the $1 \%$ program of integration of art in architecture.

The artworks consist of three high-definition digital screens of LED lights, functioning 24 hours a day. The main one is a horizontal, 42 meter-long panel of three meters high, next to the movable walkway (see figure 4).

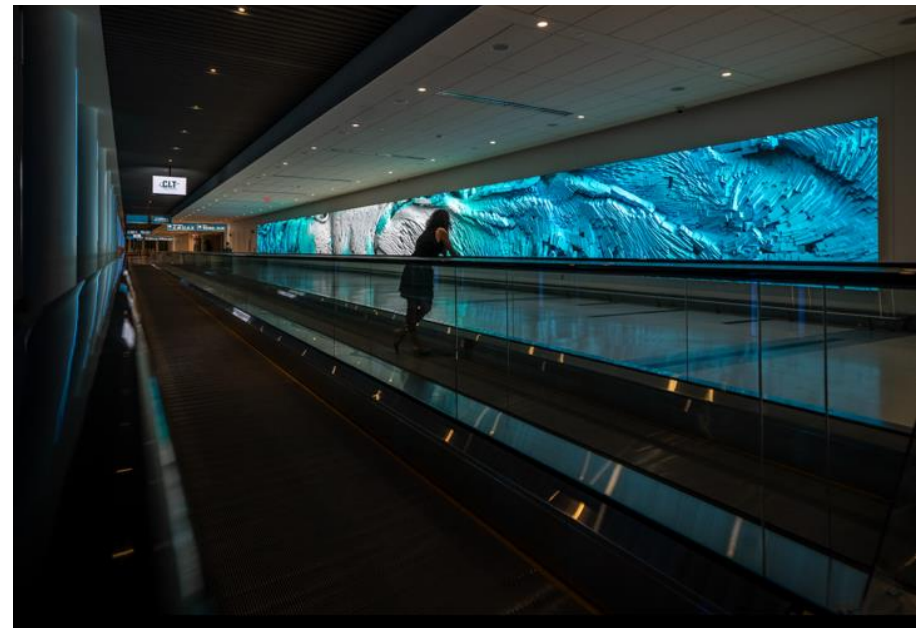

Figure 4. "Interconnected", Refik Anadol, 2018. Photo: courtesy of Refik Anadol studio.

The other two are 12 meter-long and are located around the corner in the concourse entry atrium (see figure 5). They display a 40-minute loop of moving abstract forms made of multi-million particles, each one representing a single operation directly linked to the airport. The visual artwork is divided in three "chapters": 1-Fluid Structures, 2-Impossible Materials and 3-Data Poems. The forms represented are abstract, like cloud formations or waves, others with shapes like spheres or cubes. "Along with the unique forms and motions of each chapter, variations in texture and color within each chapter add an additional layer of real-time response to the data," Anadol said in his artist statement. (ASC Charlotte, 2018) 


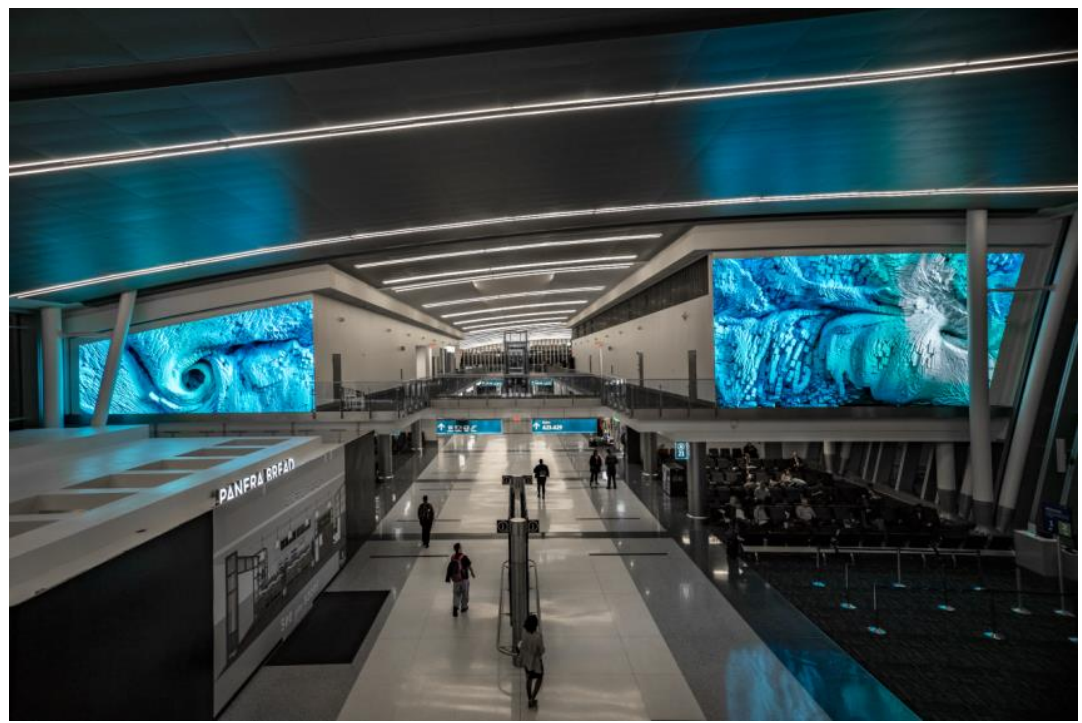

Figure 5. “Interconnected”, Refik Anadol, 2018. Photo: courtesy of Refik Anadol studio.

Data are collected in and around the airport: from air-traffic tracking software and airline flight information to the baggage handling systems, parking and ground shuttle transportation throughout the airport campus. The busiest the airport is, the denser the sculpture gets with faster movements, therefore reflecting the rhythm of the place. But data are cyclically collected during the 90 days previous to their display for security reason. Therefore, the same visualization is never repeated because the source changes. The artwork requires one of the fastest computers to treat those data with a custom-made software.

The airport is a place of transit, therefore it either makes a first impression on a traveler or can leave a lasting impression of a place. An airport is considered by the anthropologist Marc Augé as a "non-place" (Augé, 1995), which "cannot be defined as relational, or historical, or concerned with identity" (p. 77). But the transit places are now subject to a renewal ("Renouveau des lieux de transit (gares, stations de métro, aéroports...)", 2017), and produce identity and anchor, giving it an anthropological meaning through, for example, the use of art. Some airports, like Amsterdam Schiphol or Paris Charles-deGaulle, have small museum spaces, others display artworks and installations. For example, San Jose's airport displays a data-sculpture called "eCloud", hanging polycarbonate tiles that respond to the weather conditions from around the world by transitioning from transparent to opaque. In 2015, the studios Moment Factory were commissioned to provide a better experience to LAX airport with different immersive environments.

"Interconnected" offers an immersive digital experience to the traveler by transforming its surroundings in a poetic space. This self-referential artwork reveals the airport as a living organism (as the previous case did), giving the viewer a new form of storytelling of this space. Visible from outside the terminal through the glass window, it compels the future travelers before entering this space, already participating in the future display of their movements.

The data used are temporary, within a specific period of time, even though they are dynamic, cyclically renovated. They are limited to a specific space, which they refer to, but in a metaphorical way:

By translating the logic of a new media technology into spatial design, [the artist] explores how our experience of space is changing now that digital objects 
permeate our lives, how media technologies have changed our conceptualizations of space and how architecture is embracing these shifts. (ASC Charlotte, 2018)

The blending of the data in movements and shapes without decomposing them by their nature are not made to be understood by the viewer. In this case, we could refer as an "infrastructure placemaking", as it contributes to the enhancement of a "non-place" by giving it a semantic complexity through poetics and aesthetics.

While "Living connections" was the largest connected bridge, this artwork is presented as the largest data-driven digital public art installation in United States at the time of its realization. As with iconic architecture, it enhances the creation through a unique feature that gives an added value while transforming the experience of the space.

\subsection{We are nature}

In 2018, a 56-storey skyscraper, designed by Arney Fender Katsalidis (AFK) was inaugurated in downtown Calgary. Brookfield Place Calgary, now the tallest building of Western Canada, provides more than 130,000 square meters of office space and it hosts one of the main North American oil company. Indeed, Alberta's capital development is closely related to the petroleum industry, thanks to the exploitation of its oil and gas resources since the fifties, boosted after the Arab Oil Embargo of 1973.

The whole Brookfield place development includes a 2,000 square meters multi-used plaza that provides a public space meant to be used by residents, tourists and workers. The building is connected to the city with the integration of the elevated pedestrian walkway called +15 Skywalk, which passes through the tower, and by the Calgary Light Rail Transit system.

Brookfield, with properties in various North American cities, has had a division dedicated to arts for 25 years, Arts Brookfield. They commissioned a public artwork to be displayed in the south lobby of BPC and in the plaza, with the support of Calgary's Public Art Program. The artists Benjamin Rubin (director of The Center for Data Arts at The New School, CDA) and data artist Jer Thorp (of the Office for Creative Research, OCR) conceived a data-based permanent public artwork for the place, officially opened in Spring 2018.

The artwork, called "Herald/Harbinger", is displayed in downtown Calgary, but combines its data between its surroundings with others from the Bow Glacier, located in the Canadian Rocky Mountains, 180 km away. During 2016-2017, the artists installed a solarpowered seismic observatory in the glacier with sensors to capture and report its perpetual changes, cracks, movements and transformation, as it is undergoes a melting process. These movements, which correspond to 54k measurements per second, are transmitted in real time through satellite and transformed into sound and moving light in the Brookfield Place. On the one hand, a $10 \mathrm{~m}$ x 10m LED array of seven sets of vertical tubes inside the lobby displays the movements with moving colored lines (see figure 6). The glacier data are represented by horizontal lines that are moving vertically. These visualizations alternate with the pedestrian movements captured on the plaza as well as the car traffic sampled at 14 locations around Calgary, rendered on the tubes as lines that move vertically, as if they were using roadways. 


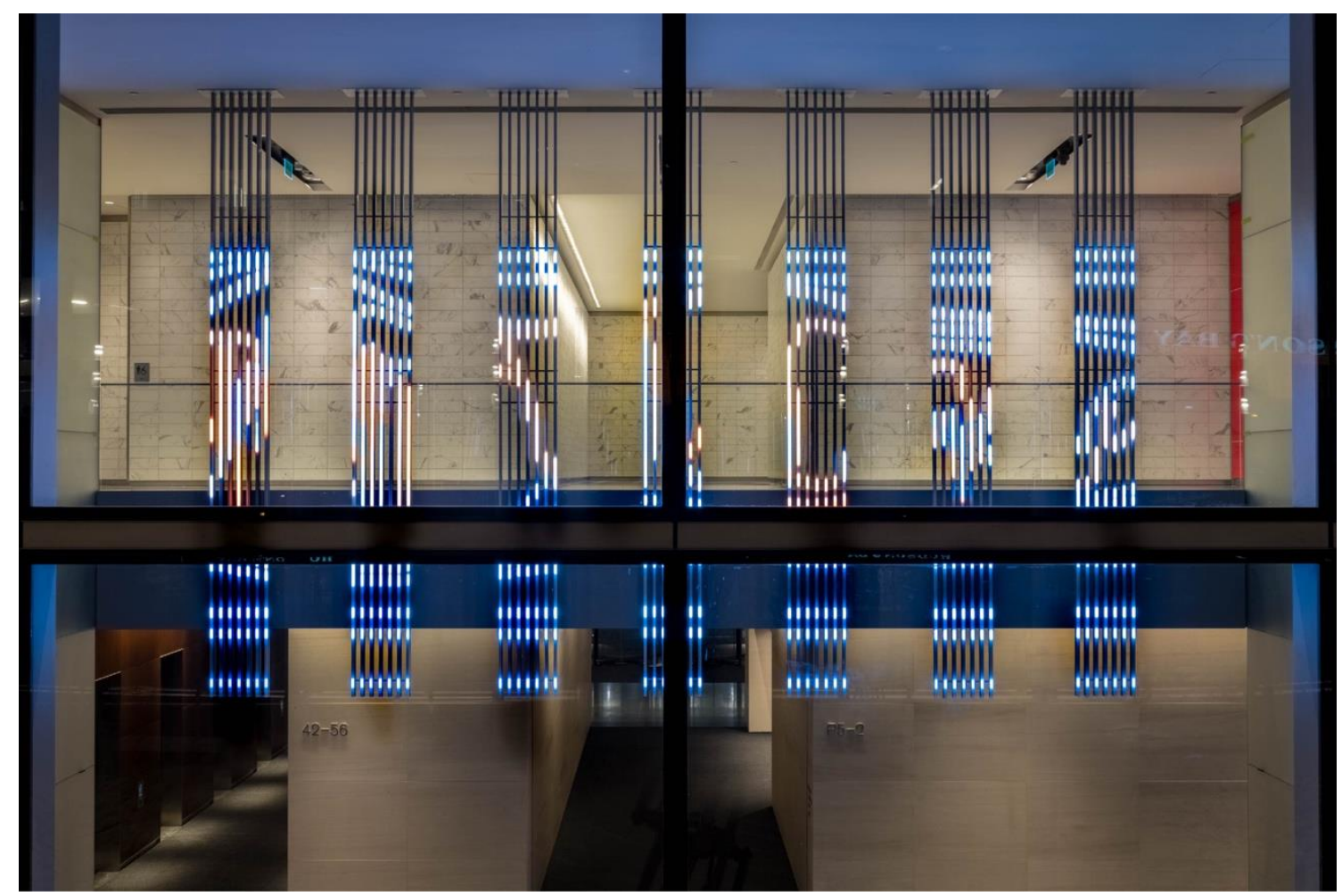

Figure 6. “Herald/Harbinger”, Ben Rubin \& Jer Thorp, 2017. Photo: (c 2019 Brett Gilmour.

On the other hand, the artwork extends on the plaza. The glacier data are sonified through 16 speakers installed on the plaza, creating a soundscape that represents ice and water. At the same time, static data, representing the flow of the glacier sliding to Bow Lake, are embedded on the granite surface of the plaza through curved lines (see figure 7).

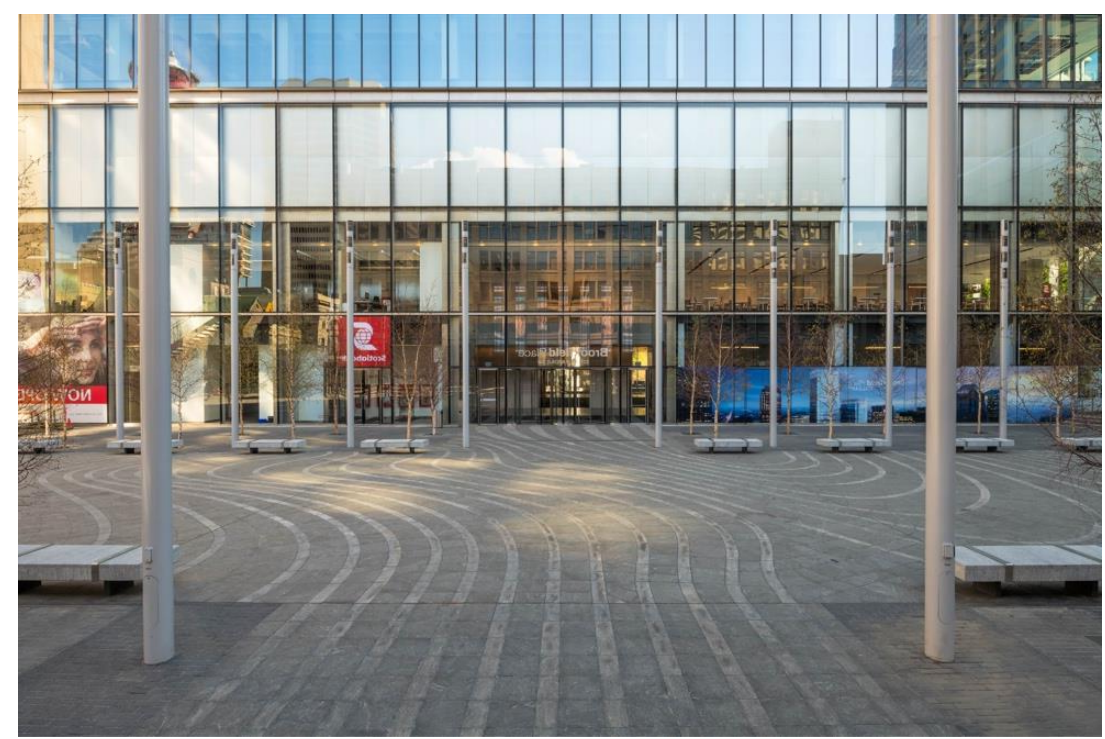

Figure 7. "Herald/Harbinger", Ben Rubin \& Jer Thorp, 2017. View of the plaza. Photo: (C 2019 Brett Gilmour.

As with the previous artworks, "Herald/Harbinger" is mainly translating real-time data, so apart from the design on the ground, it is in constant change and never project the same patterns. It responds to its immediate surroundings but also to another geographicaldetermined area, that is, the glacier. It is made by living data, from environmental nature 
but also biological, with the movements of the pedestrians. The non-living data are taken from the car traffic. The localization of both sites where data are mined and displayed, but most specially the fact that they are put in relation through the artwork, are central to the artwork. The Bow Glacier is directly linked to the city of Calgary, as its meltwater is one of the essential sources of fresh water in western Canada and crosses the city in the Bow river. Its melt is strongly affected by global changes and the fact that its activity is linked with downtown busy area of the epicenter of the Canadian oil industry is a fact that cannot be ignored.

Therefore, it bears a strong environmental message towards the community (and the industries), though it does not hold by any means a doctrinal or didactic approach. The lights movements in the lobby might recall the activity of a cardiogram, but instead of "measuring a birth, it is measuring a death" (Thorp, 2018: para.16). The name of the artwork, "Herald/Harbinger", gives a hint on the decline it reports on the dawn of Earth's Anthropocene period (Arts Brookfield, n.d.), Herald being the one that conveys news or proclaims, Harbinger giving a warning or prediction of something ("Merriam-Webster online dictionnary," n.d.). Here, the famous "medium is the message" of Marshall McLuhan (1969) takes on its full sense.

The intertwining of human activity of the city with the activity of nature reflects how one impacts on the other, but also states the human factor both as the problem and part of the solution. "Herald/Harbinger" offers an experience to the passerby or the worker through acoustic and visual medium. By also collecting its data on movements, the artwork involves its viewer in a global reflection: "More than ever before, public artworks are stimulating and inviting active dialogue among viewers rather than just passive observation, thereby fostering social interaction that can even lead to a sense of social cohesion among the viewers themselves." (Kent \& Nikitin, 2011: 17) The fact that the individual data on pedestrians are mixed with others like traffic and environmental issues makes it impossible for the viewer to know its singular incidence on the dynamism of the artwork, as shown in the two previous cases. However, the artwork also offers an individual and personal experience of the plaza, as well as a collective engagement through interactivity.

At the same time, the artwork is in line with the Calgary Civic Arts Policy as stated in 2004, which recognizes the importance of arts in the development of a community and to the local economy, therefore contributing to a larger cultural placemaking strategy. At the specific scale of its location, the artwork blurs the frontiers between interior and exterior, the plaza offering an extension of the light visualization of the glacier with a static visualization of its sliding path to the lake. Inversely, the exterior city activity is also reflected throughout the light, placed in the lobby. "Herald/Harbinger" is enhanced in art and the city, a curated walking tour that offers information on a selection of artworks in downtown Calgary with QR codes.

\section{CONCLUSION: THE CONNECTED CITY}

This paper aimed at contributing to the field of digital urban public art by defining data art, its specificities and its role in different types of placemaking through three different case studies. Data art, as a new form of digital urban art offers a new experience to the viewer by adding a complex semantic and sensorial layer to the existing urban fabric and spaces. It reaffirms public space as socially constructed (Lefebvre, 1974). With the virtual 
space opened by the relation between the place and time of data collection and their display, it provides a key to digital placemaking, which encompasses the virtual component of data art. Located in three different areas, such as an iconic bridge, an airport and a link between city and nature, each case study illustrated a specific way to connect the artwork to its surrounding through the content (types of data), transforming the perception of the site.

The first case, "Living Connections", developed the reflection of the surrounding through spectacle. However, the geographical area of its data collection is not well defined, so the reflection is open to the concepts that revolve as satellites around the site rather than directly linking to it. The explanation about the correlation between the data feed and the visuals makes it more complex to interpret. The spectacle is further enhanced, as it monumentalizes an already consolidated icon of the city. The second case, "Interconnected", proposed a poetic self-reflection of a place traditionally considered as a "non-place", involving an infrastructure placemaking that injects meaning to the airport and transforming its experience. The different data do not represent real-time activity, but they are constantly modified. The artwork therefore gives a hint of the intensity of the airport activity, but mostly provides an aesthetic experience. Finally, the last example "Herald/Harbinger" showed how a real-time data connection between nature and city can involve community in a general issue such as the global change, which affect us at all scale. The three of them provide a storytelling of their place, as well as a unique experience to the viewer, even though they have been designed following different approaches, from spectacle to poetry and raised awareness. Data is an increasing gold mine for artists to play with and construct new narratives. From wearable art to onscreen visualization, data art takes different formats and deals with a variety of content, related to the data it uses as material. It can raise questions, express concerns or communicate issues (for example environment, mobility, security, society, etc.) with an aesthetic approach and it is not so much related to the accurate transmission of information. Data art is not a mainstream practice yet as a public form of art, and it presents a big potential to use data for an informative purpose and at the same time to revitalize an urban area. For instance, using data gathered on visitors flows in a tourism site and exhibit it as a work of art that people could consult at the same time in order to dispatch the visitors in less-crowded time windows.

Data art offers good opportunities and potential for digital placemaking in public spaces with a dynamic content that responds to the reality where the data are collected, in a sustainable way. But as an emerging practice, data art might not be fully understood by the public (visitor, user, passerby...). The challenge is to fully grasp the complexity that it provides in order to appreciate all the layers of this new storytelling about a city or a space, hence the need for some kind of mediation. With data art, viewers are not passive, "they often engage their own identity, or construct their difference, through several art reception strategies and adaptation of art works to their own perspectives, during their visit to an artistic space." (Andrade, 2018: 7). How do the public engage with those new types of art? Does public data art bring a paradigmatic change in public art through its connected nature? Further studies on its reception could bring a new light on the way the space is perceived, as well as the connection between the content and the lived experience.

\section{References}

Andrade, P. (2018). Cultural E-Tourism Depicted by Digital Discourse: Innovative Mobilities at 
Urban E-Heritage Networks. In M. Bielania-Grajewska \& M. E. Cortés de los Ríos (Eds.), Innovative perspectives on tourism discourse (pp. 1-17). Hershey, PA: Business Science Reference.

Appadurai, A. (1990). Disjuncture and Difference in the Global Cultural Economy. Theory Culture Society, 7, 295-310.

Arruabarrena, B. (2015). Datavisualisation : principes, enjeux et perspectives pour des utilisateurs non experts. In É. Broudoux \& G. Chartron (Eds.), Big Data - Open Data : Quelles valeurs ? Quels enjeux? (pp. 151-163). Louvain-la-Neuve: De Boeck Supérieur.

Arts Brookfield. (n.d.). Herald/Harbinger. Retrieved February 5, 2019, from https://www.artsbrookfield.com/art collection/herald-harbinger-2/

ASC Charlotte. (2018). New Installation at Charlotte Douglas International Airport Transforms Airport Operations Data into Highly Visible Work of Art. Retrieved February 5, 2019, from https://www.artsandscience.org/new-installation-at-charlotte-douglas-international-airporttransforms-airport-operations-data-into-highly-visible-work-of-art/

Augé, M. (1995). Non-Places. introduction to an anthropology of supermodernity. London, New York: Verso.

Bihanic, D. (2018). Data design: les données comme matériau de création. Paris: Alternatives et Fondation EDF.

CLT Art Program. (n.d.). Retrieved on January 3, 2019, from https://www.cltairport.com/AboutCLT/Pages/Arts\%20and\%20Exhibits.aspx.

Corby, T. (2008). Landscapes of Feeling, Arenas of Action: Information Visualization as Art Practice. Leonardo, 41(4), 460-467.

Everett-Green, R. (2017, May 19). Montreal's Cartier Bridge is all lit up, but what's the purpose? The Globe and Mail. Retrieved from https://www.theglobeandmail.com/arts/what-is-montrealsliving-connections-light-show-trying-to-say/article35059884/.

Evers, L., \& Nack, F. (2016). Data Aesthetics-The Ethics and Aesthetics of Big Data Gathering seen from the Artists Eye. In 2016 ACM on Multimedia Conference (pp. 779-780). ACM Digital Library.

Fedorova, K. (2012). New media art and the technological sublime. Acta Academiae Artium Vilnensis, 67, 33-44.

Fortin, C. (2016). Recasting the data sublime in media architecture. In Proceedings of the 3rd Conference on Media Architecture Biennale - MAB (pp. 1-10). New York: ACM Press.

Freeman, J., Starks, G., \& Sandler, M. (2018). A Concise Taxonomy for Describing Data as an Art Material. Leonardo, 51(1), 75-79.

Grugier, M. (2016). The digital age of data art. In TechCrunch. Retrieved from https://techcrunch.com/2016/05/08/the-digital-age-of-data-art/?guccounter=2.

Kent, F., \& Nikitin, C. (2011). Collaborative Placemaking: Good public art depends on good public spaces.: Public Art Review, 45 (1), 17.

Kosara, R. (2007). Visualization Criticism - The Missing Link Between Information Visualization and Art. In 11th International Conference Information Visualization (IV'07) (pp. 631-636). IEEE.

Lefebvre, H. (1974). La production de l'espace. Paris: Anthropos.

Legrady, G., \& Forbes, A. G. (2017). Data in Context: Conceptualizing Site-Specific Visualization Projects. Leonardo, 50(2), 200-204.

Lew, A. A. (2017). Tourism planning and place making: place-making or placemaking? Tourism Geographies, 19(3), 448-466.

Li, Q. (2018). Data visualization as creative art practice. Visual Communication, 17(3), 299-312.

MacCannell, D. (2013). The tourist: a new theory of the leisure class ([Rev. ed.].). Berkeley: University of California Press.

Machin, A. (2000). Datascapes: Tourism and the Historical Geography of Knowledge. Tourism and Hospitality Research, 2(4), 357-375.

Manovich, L. (2002). “Data Visualization as New Abstraction and Anti-Sublime”. Retrieved from http://manovich.net/content/04-projects/040-data-visualisation-as-new-abstraction-andanti-sublime/37 article 2002.pdf.

Manovich, L. (2006). The poetics of augmented space. Visual Communication, 5(2), 219-240.

Mansilla, W. A., \& Perkis, A. (2016). Technology \& Art in Stimulating Creative Placemaking in PublicUse Spaces. In Proceedings of the 2016 ACM on Multimedia Conference - MM '16 (pp. 14731474). New York : ACM Press.

Markusen, A., \& Gadwa, A. (2010). Creative Placemaking. Washington. Retrieved from https://www.arts.gov/sites/default/files/CreativePlacemaking-Paper.pdf 
McCormack, J., \& Dorin, A. (2001). Art, Emergence, and the Computational Sublime. In A. Dorin (Ed.), Proceedings of The Second International Conference on Generative Systems in the Electronic Arts (pp. 67-81). Vic, Australia: Monash University Publishing.

McLuhan, M. (1969). Understanding media : the extensions of man. London: Sphere Books Limited.

McQuire, S. (2008). The Media City: Media, Architecture and Urban Space. Los Angeles: Sage.

Merriam-Webster online dictionary. (n.d.). Retrieved February 17, 2019, from https://www.merriam-webster.com/.

Moment Factory. (2019). Jacques Cartier Bridge Lights. Retrieved February 17, 2019, from https://momentfactory.com/work/all/all/jacques-cartier-bridge-illumination.

Pop, S., Toft, T., Calvillo, N., \& Wright, M. (Eds.). (2016). What urban media art can do: why when where \& how. Stuttgart: Avedition.

Pop, S., Tscherteu, G., Stalder, U., \& Struppek, M. (2012). Urban Media Cultures. Ludwigsburg: Avedition.

Ramirez Gaviria, A. (2008). When Is Information Visualization Art? Determining the Critical Criteria. Leonardo, 41(5), 479-482.

Renouveau des lieux de transit (gares, stations de métro, aéroports...). (2017). Revue Espaces, (334).

Richards, G. (2016). Placemaking in Barcelona: from 'Paris of the south' to 'capital of the mediterranean.' MMnieuws. NHTV: Cities in Transition \& Leisure, 8-9.

Silberberg, S. (2013). Places in the Making: How Placemaking Builds Places and Communities. Retrieved from http://dusp.mit.edu/cdd/project/placemaking.

Starrett, C., Reiser, S., \& Pacio, T. (2018). Data Materialization: A Hybrid Process of Crafting a Teapot. Leonardo, 51(4), 381-385.

Strydom, W., Puren, K., \& Drewes, E. (2018). Exploring theoretical trends in placemaking: towards new perspectives in spatial planning. Journal of Place Management and Development, 11(2), $165-180$.

Thorp, J. (2018). Sounding the Bow. How we moved a vanishing glacier to the center of Canada's fastest growing city. Retrieved from https://medium.com/@blprnt/sounding-the-bow628f92beb0b7.

Tomitsch, M. (2016). Communities, Spectacles and Infrastructures: Three Approaches to Digital Placemaking. In S. Pop, T. Toft, N. Calvillo, \& M. Wright (Eds.), What urban media art can do : why when where \& how (pp. 339-354). Stuttgart: Avedition.

Tufte, E. (1990). Envisioning information. Cheshire: Graphics.

Urbonas, G., Lui, A., \& Freeman, L. (Eds.). (2017). Public space? Lost and found. Cambridge: SA $+\mathrm{P}$ Press;MIT School of Architecture and Planning.

Viégas, F. B., \& Wattenberg, M. (2007). Artistic Data Visualization: Beyond Visual Analytics. In D. Schuler (Ed.), Online Communities and Social Computing. OCSC 2007. Lecture Notes in Computer Science, vol 4564 (pp. 182-191). Berlin, Heidelberg: Springer.

Wyckoff, M. A. (2014). Definitions of placemaking: Four different types. Planning \& Zoning News, 32(3), 1-10. Retrieved from www.miplace.org. 